\title{
The sustainable future of open-pit trucks operation
}

\author{
Yurii Monastyrskiy ${ }^{1,}$, Volodymyr Sistuk $^{1, *}$, Volodymyr Potapenko ${ }^{1}$, and Ivan Maksymenko ${ }^{1}$ \\ ${ }^{1}$ Kryvyi Rih National University, Automobile Facilities Department, 44 Pushkin Str., 50002, Ukraine
}

\begin{abstract}
Open-pit truck technical operation determines mined bulk transportation effectiveness increasing equipment's commercial operation duration based on a robust strategy of vehicle's maintenance, early and high-quality diagnostics, upkeep and recovery. Developed mathematical model of BelAZ open-pit truck operation for various levels of organization of servicing replicates a Markov process in the system of technological automotive transport considering possibilities of vehicle states with time and steady-state condition. The performance of open-pit trucks was consistently evaluated and the model of the technological automotive transport system was synthesized. The validation analysis of the obtained model showed its suitability for optimization of open-pit truck performance. The calculated optimal controlling actions on the open-pit truck allow developing an algorithm and technique for dynamic adjustment of parameters of maintenance, diagnostics and repair of BELAZ open-pit trucks that will become the basis for a sustainable future of industrial transport technical operation.
\end{abstract}

\section{Introduction}

A status of open-pit mining is growing; the percentage of technological automobile transport that is a part of the transport and handling equipment of an open pit is increasing. The modern deep open pit is an enormous power-intensive enterprise that includes large truck fleet aimed to appropriate mined bulk transportation. Processing of large mineral resources volumes from openpit mining causes the side effects related especially to its transportation [1-3]. Due to the deep depth (more than 300 meters) and the possibility of further advance at the lowest level of open pits in Ukraine as well as in the world, bulk transportation becomes increasingly difficult. From this, it follows that the problem of developing reliable and costeffective systems for mined bulk transportation is especially acute.

Of more than two thousand BELAZ open-pit trucks works at Ukrainian enterprises representing above $90 \%$ from the overall number of open-pit trucks of all manufactures introduced to our market. The largest business entities for BELAZ equipment operation are iron ore mining and processing enterprises of the city of Kryvyi Rih where about two-thirds of the overall number of Ukrainian open pit truck's fleet are accumulated including above 200 vehicles with electromechanical transmission and payload capacity of 120-220 tones that arrange for base quantity of mined bulk transportation. In 2018 the enterprises of Kryvyi Rih iron ore basin purchased 52 vehicles of BELAZ whereof 31 pit truck BELAZ-75131 with payload capacity of 130 tones [4].

The feature of the system of technological automotive transport (STAT) is the fact that it consists of an open-pit truck fleet and operates compatibly certain cycles, which are determined following a haulage roads design. The analytical review of the basic works, which are focused on technological automotive transport maintenance system evolution, has allowed establishing the too low level of its organization concerning open-pit trucks especially with the huge payload capacity [5-7].

Despite a considerable body of theoretical work existed in the technical literature [8], integrated mathematical models are currently absent that can be used to describe vehicle operations taking into consideration all engineering and resources conditions of equipment, state transition, loss of function, field maintenance and at the same time an industrial transport service costs minimization.

Multipronged implementation, system approach to open-pit truck maintenance improvement is evident as synchronous evolution of diagnostic and monitoring systems within the framework of an actual state service development considering all the advantages of scheduled preventive maintenance.

The reliability of the system of open pit's technological automotive transport is the main indicator for the cost-effective management of the pit trucks operation as well as for the production as a whole.

Long-term and reliable operation of open-pit trucks becomes possible provided timely, systematic and highquality maintenance and repair; therefore, validation of operating parameters of technological vehicles in deep open pits is a crucial task.

\section{Formulation of the problem}

The goal of the research is an enhancement of operating efficiency of technological automotive transport of deep open pits via a solid approach to its maintenance

\footnotetext{
* Corresponding author: monastirskiy08@ukr.net
} 
parameters. The problem of a maintenance system improvement is qualified as the planning and design of vehicle's maintenance management technique, minimization of unit transportation costs. The study subject is a deep open pit technological automotive transport technical maintenance. The research also focuses on synergies between maintenance parameters and technical and economic features of deep open pit technological automotive transport.

\section{Materials and methods}

The technological states of open-pit trucks change over time randomly and unexpectedly. Importantly it would be safe to assume that there is the relationship of the BELAZ open-pit truck technological state in the future on its current state and regardless of how and when that state was reached at this point. With the view to the mathematical treatment of such technological states of the open-pit truck, it is considered appropriate to use a mathematical apparatus known as "Markov random processes". Besides, having regard to the three technological state subsystems of the open-pit truck are considered, mathematical modelling using the "Markov process with discrete states and continuous-time" pattern can be applied.

Figure 1 shows a marked graph of the subsystems of technological states of BELAZ open-pit truck during mining positing that the probability of being each of them is described by the Kolmogorov differential equation set:

$$
\left\{\begin{array}{l}
\frac{d P_{0}}{d t}=-\left(\lambda+\omega_{1}\right) P_{0}+\mu_{1} P_{1}+\mu_{2} P_{2} ; \\
\frac{d P_{1}}{d t}=\lambda P_{0}-\left(\mu_{1}+\omega_{2}\right) P_{1} \\
\frac{d P_{2}}{d t}=\omega_{1} P_{0}+\omega_{2} P_{1}-\mu_{2} P_{2}
\end{array}\right.
$$

where $P_{0}=P_{0}(t)$ - is the possibility of machine operation, $P_{1}=P_{1}(t)$ - is the possibility of scheduled maintenance, $P_{2}=P_{2}(t)-$ is the possibility of unscheduled operating repair.

At the initial time, it is expected that the open-pit truck is in working order:

$$
P_{0}(t=0)=1 ; P_{1}(t=0)=0 ; P_{2}(t=0)=0 .
$$

While the requirement of completeness of the STAT must also be fulfilled:

$$
P_{0}(t)+P_{1}(t)+P_{2}(t)=1
$$

Equations (1) and initial conditions (2) determine the Cauchy problem. In the furtherance of this goal, it is required to ensure the general solution of the differential equation system (1) and then, according to the initial conditions (2), determine the partial solution.

The solution of system (1) can be presented as follows:

$$
P_{i}(t)=X_{i} \cdot e^{\theta_{i} \cdot t} ;(i=0,1,2)
$$

Substituting equation (4) into the system of differential equations (1), a homogeneous system of linear equations is depicted:

$$
\left\{\begin{array}{c}
-\left(\lambda+\omega_{1}+\theta\right) X_{0}+\mu_{1} X_{1}+\mu_{2} X_{2}=0 \\
\lambda X_{0}-\left(\mu_{1}+\omega_{2}+\theta\right) X_{1}=0 \\
\omega_{1} X_{0}+\omega_{2} X_{1}-\left(\mu_{2}+\theta\right) X_{2}=0
\end{array}\right.
$$

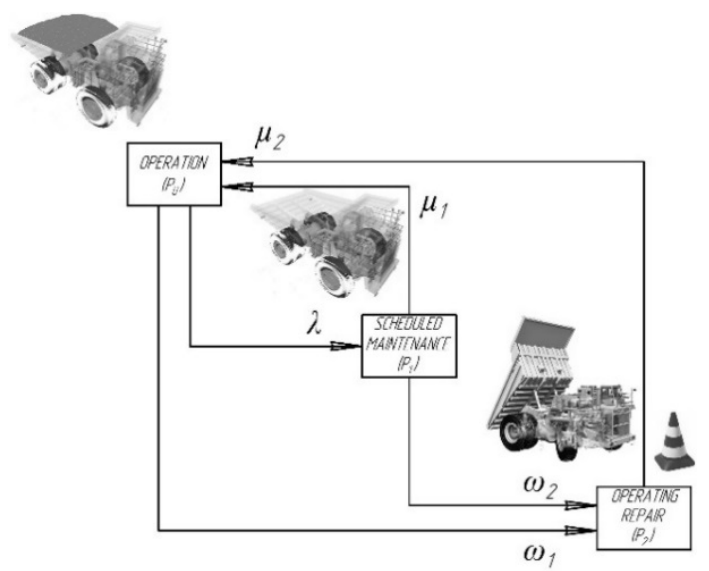

Fig. 1. The marked graphic chart of technological states of BelAZ open-pit truck: $\lambda$ - is the open-pit truck transition rate from functional condition to state of scheduled maintenance and repairs; $\omega_{1}-$ is the open-pit truck transition rate from functional condition to state of unscheduled operating repairs; $\omega_{2}$ - is the open-pit truck transition rate from state of maintenance and repair to operating repair; $\mu_{1}, \mu_{2}-$ are the transition rates of open-pit trucks restoration to functional condition from states of maintenance and operating repair respectively.

For a homogeneous system of linear equations (5) its determinant must be zero to have a non-trivial solution:

$$
\left|\begin{array}{ccc}
-\left(\lambda+\omega_{1}+\theta\right) & \mu_{1} & \mu_{2} \\
\lambda & -\left(\mu_{1}+\omega_{2}+\theta\right) & 0 \\
\omega_{1} & \omega_{2} & -\left(\mu_{2}+\theta\right)
\end{array}\right|=0 .
$$

Removing determinant (6), an equation for eigenvalues estimation is specified:

$$
\begin{gathered}
\theta^{3}+\theta^{2}\left(\lambda+\omega_{1}+\omega_{2}+\mu_{1}+\mu_{2}\right)+ \\
+\theta\left(\lambda \mu_{2}+\omega_{2} \mu_{2}+\mu_{1} \mu_{2}+\lambda \omega_{2}+\omega_{1} \mu_{1}+\omega_{1} \omega_{2}\right)=0 .
\end{gathered}
$$

The solution of this equation is as follows

$$
\begin{gathered}
\theta_{1}=0 ; \\
\theta_{2}=\frac{-\left(\lambda+\omega_{1}+\omega_{2}+\mu_{1}+\mu_{2}\right)-\sqrt{D}}{2} ; \\
\theta_{3}=\frac{-\left(\lambda+\omega_{1}+\omega_{2}+\mu_{1}+\mu_{2}\right)+\sqrt{D}}{2},
\end{gathered}
$$

where $\quad D=\left(\lambda+\omega_{1}+\omega_{2}+\mu_{1}+\mu_{2}\right)^{2}-4\left(\lambda \mu_{1}+\right.$ $\left.+\omega_{2} \mu_{2}+\mu_{1} \mu_{2}+\lambda \omega_{2}+\omega_{1} \mu_{1}+\omega_{1} \omega_{2}\right)$.

Conversely eigenvectors are estimated corresponding to the determined eigenvalues (8) by substituting these values into a system of linear equations (5).

The system of two equations is obtained for the values $\theta=\theta_{i}$ :

$$
\left\{\begin{array}{c}
-\left(\lambda+\omega_{1}+\theta_{i}\right) X_{0}+\mu_{1} X_{1}+\mu_{2} X_{2}=0 \\
\lambda X_{0}-\left(\mu_{1}+\omega_{1}+\theta_{i}\right) X_{1}=0
\end{array} .(i=1,2,3)\right.
$$


Considering $X_{0}=1$, by solving equation (9) the coordinates of the eigenvector corresponding to the eigenvalue are found:

$$
\begin{gathered}
x_{1}^{(i)}=1 ; \\
x_{2}^{(i)}=\frac{\lambda}{\mu_{1}+\omega_{1}+\theta_{i}} ;(i=1,2,3) \\
x_{3}^{(i)}=\frac{\theta_{i}^{2}+\theta_{i}\left(\lambda+\mu_{1}+2 \omega_{1}\right)+\omega_{1}\left(\lambda+\mu_{1}+\omega_{1}\right)}{\mu_{2}\left(\mu_{1}+\omega_{1}+\theta_{i}\right)} .
\end{gathered}
$$

Taking into account equation (10), a complementary solution of differential equation system (1) is written:

$$
\begin{gathered}
P_{0}(t)=C_{1}+C_{2} e^{\theta_{2} t}+C_{3} e^{\theta_{3} t} \\
P_{1}(t)=\frac{\lambda}{\mu_{1}+\omega_{1}} C_{1}+\frac{\lambda}{\mu_{1}+\omega_{1}+\theta_{2}} C_{2} e^{\theta_{2} t}+ \\
+\frac{\lambda}{\mu_{1}+\omega_{1}+\theta_{3}} C_{3} e^{\theta_{3} t} ; \\
+\frac{\theta_{2}^{2}+\theta_{2}\left(\lambda+\mu_{1}+2 \omega_{1}\right)+\omega_{1}\left(\lambda+\mu_{1}+\omega_{1}\right)}{\mu_{2}\left(\mu_{1}+\omega_{1}+\theta_{2}\right)} C_{2} e^{\theta_{2} t}+ \\
+\frac{\theta_{3}^{2}+\theta_{3}\left(\lambda+\mu_{1}+2 \omega_{1}\right)+\omega_{1}\left(\lambda+\mu_{1}+\omega_{1}\right)}{\mu_{2}\left(\mu_{1}+\omega_{1}+\theta_{3}\right)} C_{3} e^{\theta_{3} t},
\end{gathered}
$$

where $C_{1}, C_{2}, C_{3}$ - are the arbitrary constants.

To find arbitrary constants, initial condition is used (2), which gives a system of linear equations:

$$
\left\{\begin{array}{l}
C_{1}+C_{2}+C_{3}=1 ; \\
\frac{1}{\mu_{1}+\omega_{1}} C_{1}+\frac{1}{\mu_{1}+\omega_{1}+\theta_{2}} C_{2}+\frac{1}{\mu_{1}+\omega_{1}+\theta_{3}} C_{3}=0 ; \\
\frac{\omega_{1}\left(\lambda+\mu_{1}+\omega_{1}\right)}{\mu_{2}\left(\mu_{1}+\omega_{1}\right)} C_{1}+\frac{\theta_{2}^{2}+\theta_{2}\left(\lambda+\mu_{1}+2 \omega_{1}\right)+\omega_{1}\left(\lambda+\mu_{1}+\omega_{1}\right)}{\mu_{2}\left(\mu_{1}+\omega_{1}+\theta_{2}\right)} C_{2}+ \\
+\frac{\theta_{3}^{2}+\theta_{3}\left(\lambda+\mu_{1}+2 \omega_{1}\right)+\omega_{1}\left(\lambda+\mu_{1}+\omega_{1}\right)}{\mu_{2}\left(\mu_{1}+\omega_{1}+\theta_{3}\right)} C_{3}=0 .
\end{array}\right.
$$

Solving system (12), we find

$$
\left\{\begin{array}{c}
C_{1}=\frac{\left(\omega_{2}+\mu_{1}\right) \mu_{2}}{\lambda \mu_{2}+\omega_{2} \mu_{2}+\mu_{1} \mu_{2}+\lambda \omega_{2}+\omega_{1} \mu_{1}+\omega_{1} \omega_{2}} \\
C_{2}=\frac{\left(\omega_{1}+\mu_{1}+\theta_{2}\right)\left(\lambda+2 \omega_{1}+\mu_{1}+\theta_{3}\right)}{\theta_{2}\left(\theta_{2}-\theta_{3}\right)} \\
C_{3}=\frac{\left(\omega_{1}+\mu_{1}+\theta_{3}\right)\left(\lambda+2 \omega_{1}+\mu_{1}+\theta_{2}\right)}{\theta_{3}\left(\theta_{3}-\theta_{2}\right)}
\end{array}\right.
$$

Substituting equation (13) into complementary solution (11), handling the Cauchy problem is as follows:

$$
\begin{aligned}
& P_{0}(t)=\frac{\left(\omega_{2}+\mu_{1}\right) \mu_{2}}{\lambda \mu_{2}+\omega_{2} \mu_{2}+\mu_{1} \mu_{2}+\lambda \omega_{2}+\omega_{1} \mu_{1}+\omega_{1} \omega_{2}}+ \\
& +\frac{\left(\omega_{1}+\mu_{1}+\theta_{2}\right)\left(\lambda+2 \omega_{1}+\mu_{1}+\theta_{3}\right)}{\theta_{2}\left(\theta_{2}-\theta_{3}\right)} e^{\theta_{2} t}+ \\
& +\frac{\left(\omega_{1}+\mu_{1}+\theta_{3}\right)\left(\lambda+2 \omega_{1}+\mu_{1}+\theta_{2}\right)}{\theta_{3}\left(\theta_{3}-\theta_{2}\right)} e^{\theta_{3} t} ; \\
& P_{1}(t)=\frac{\lambda \mu_{2}}{\lambda \mu_{2}+\omega_{2} \mu_{2}+\mu_{1} \mu_{2}+\lambda \omega_{2}+\omega_{1} \mu_{1}+\omega_{1} \omega_{2}}+ \\
& +\frac{\lambda\left(\omega_{1}+\mu_{1}+\theta_{2}\right)\left(\lambda+2 \omega_{1}+\mu_{1}+\theta_{3}\right)}{\left(\omega_{1}+\mu_{1}+\theta_{2}\right) \theta_{2}\left(\theta_{2}-\theta_{3}\right)} e^{\theta_{2} t}+ \\
& +\frac{\lambda\left(\omega_{1}+\mu_{1}+\theta_{3}\right)\left(\lambda+2 \omega_{1}+\mu_{1}+\theta_{2}\right)}{\left(\omega_{1}+\mu_{1}+\theta_{3}\right) \theta_{3}\left(\theta_{3}-\theta_{2}\right)} e^{\theta_{3} t} ;
\end{aligned}
$$

$$
\begin{aligned}
& P_{2}(t)=\frac{\lambda \omega_{2}+\omega_{1} \omega_{2}+\omega_{1} \mu_{1}}{\lambda \mu_{2}+\omega_{2} \mu_{2}+\mu_{1} \mu_{2}+\lambda \omega_{2}+\omega_{1} \mu_{1}+\omega_{1} \omega_{2}}+ \\
& +\frac{\theta_{2}^{2}+\theta_{2}\left(\lambda+2 \omega_{1}+\mu_{1}\right)+\omega_{1}\left(\lambda+\omega_{1}+\mu_{1}\right)\left(\lambda+2 \omega_{1}+\mu_{1}+\theta_{3}\right)}{\mu_{2} \theta_{2}\left(\theta_{2}-\theta_{3}\right)} e^{\theta_{2} t}+ \\
& +\frac{\theta_{3}^{2}+\theta_{3}\left(\lambda+2 \omega_{1}+\mu_{1}\right)+\omega_{1}\left(\lambda+\omega_{1}+\mu_{1}\right)\left(\lambda+2 \omega_{1}+\mu_{1}+\theta_{2}\right)}{\mu_{2} \theta_{3}\left(\theta_{3}-\theta_{2}\right)} e^{\theta_{3} t} .
\end{aligned}
$$

The mathematical model, which is described by functions (14), allows us to determine the probabilities of BELAZ open-pit truck being in each of the subsystems of technological state.

However, the study of the operation of open-pit truck based on the derived mathematical model is some difficult which is due to the probabilities dependence on time.

Thus, it seems advisable to consider edge steady-state operating conditions wherein the system that describes the open-pit truck operation changes their states randomly but the probability each of them is no longer dependent on time. In this case, the probability characterizes the average relative residence time of open-pit truck in this state. To calculate these probabilities, it is sufficient to equate the derivatives to zeros in formulas (1), which gives three simultaneous linear equations in three variables:

$$
\left\{\begin{array}{c}
-\left(\lambda+\omega_{1}\right) P_{0}+\mu_{1} P_{1}+\mu_{2} P_{2}=0 ; \\
\lambda P_{0}-\left(\mu_{1}+\omega_{2}\right) P_{1}=0 ; \\
\omega_{1} P_{0}+\omega_{2} P_{1}-\mu_{2} P_{2}=0 .
\end{array}\right.
$$

The resulting set of equations (15) is linearly dependent because its determinant is zero accordingly equation (6). Therefore, determining an appropriate solution is coming from the rejection of one equation and supplementing condition (2):

$$
\left\{\begin{array}{l}
-\left(\lambda+\omega_{1}\right) P_{0}+\mu_{1} P_{1}+\mu_{2} P_{2}=0 \\
\lambda P_{0}-\left(\mu_{1}+\omega_{2}\right) P_{1}=0 \\
P_{0}+P_{1}+P_{2}=1
\end{array}\right.
$$

The linear system solving (16) is as follows

$$
\begin{gathered}
P_{0}=\frac{\left(\omega_{2}+\mu_{1}\right) \mu_{2}}{\left(\lambda+\omega_{2}+\mu_{1}\right) \mu_{2}+\left(\lambda+\omega_{1}\right) \omega_{2}+\omega_{1} \mu_{1}} ; \\
P_{1}=\frac{\lambda \mu_{2}}{\left(\lambda+\omega_{2}+\mu_{1}\right) \mu_{2}+\left(\lambda+\omega_{1}\right) \omega_{2}+\omega_{1} \mu_{1}} ; \\
P_{2}=\frac{\left(\lambda+\omega_{1}\right) \omega_{2}+\omega_{1} \mu_{1}}{\left(\lambda+\omega_{2}+\mu_{1}\right) \mu_{2}+\left(\lambda+\omega_{1}\right) \omega_{2}+\omega_{1} \mu_{1}} .
\end{gathered}
$$

Formulas (17), (18), (19) determine the probabilities of open-pit being in stationary subsystems of technological states which are operation, scheduled maintenance and unscheduled operating repairs respectively.

The developed mathematical model of BELAZ openpit truck operation (17-19) for the various management levels of maintenance, diagnostic and repair reproduces the Markov process occurring at the STAT and allows calculating machine state probability with time as well as without reference to time [4]. The open-pit trucks operation is consistently studied. Modelling machine states and transitions allowed calculating time-dependent system state probabilities, empowered to formulate the purpose and the function of the income from operating surplus described by the three basic states of open-pit trucks. By varying the parameters of the function, the 
rational costs of the transportation system operation can be found [9].

As the part of developed mathematical model of transportation system of iron ore open pit that introduces technological states of the fleet of BELAZ open-pit trucks via calculation of statistically distributed numerical characteristics of these states, the management of the maintenance system is designed on the basis of economic criterion as an extremum problem subject to the constraints related to technological states of the system [10].

The analysis of the STAT of the deep open pit has allowed establishing that its control parameter, which characterizes and determines the intensity of scheduled preventive maintenance $\lambda$ (Fig. 1), especially bears on its efficiency [11]. Therefore, it seems appropriate to investigate the relationship of this parameter with other parameters that characterize the operating of technological transport of mining and processing plants of the Kryvyi Rih iron ore basin. In this regard, it is necessary to confirm the ability to control the performance of the STAT by adjustment of the governing parameter based on the regulation of the control parameters. The substantiation of maintenance intervals is one of the main procedures of open-pit trucks reliabilityassurance program and the quality policy of OJSC "BELAZ"
The technological automotive transport system took an assessment as exemplified by Central Iron Ore Enrichment Works (PJSC "Central GOK") where 5 new warranty and 44 non-warranty open-pit trucks BELAZ75131 operated during 2015 (in 22 vehicles on mining workshops with number one and two).

Non-warranty BELAZ open-pit trucks are those for which one of three events have occurred since the beginning of operation namely a calendar time of 12 months or 6,000 running hours or $60,000 \mathrm{~km}$.

The above-mentioned vehicles truck about $700 \mathrm{~m}^{3}$ of mined rock per shift and up to $1,500 \mathrm{~m}^{3}$ per day. The analysis of the performance of BELAZ trucks at the open pit of PJSC "Central GOK" indicates the STAT parametric identification applicability which will allow, drawing from relevant statistical material, determining the values of the STAT mathematical model parameters as a consequence of structural identification.

The optimality criterion is the minimum of a man-hour expenditure of the maintenance

$$
C=c_{1} \cdot N_{1} \cdot T_{1}+c_{2} \cdot N_{2} \cdot T_{2} \rightarrow \underset{\lambda, \omega_{1}, \omega_{2}, \mu_{1}, \mu_{2}}{\min }
$$

where $c_{1}$ and $c_{2}-$ are the average expenditures of maintenance and unscheduled operating repairs, manhour; $N_{k}-$ is the number of trucks in $k$-th state, $(k=1,2)$; $T_{k}$ - is the time when the trucks are in $k$-th state, $(k=1,2)$.

Table 1. BELAZ open-pit trucks fleet configuration at PJSC "Central GOK" in 2015.

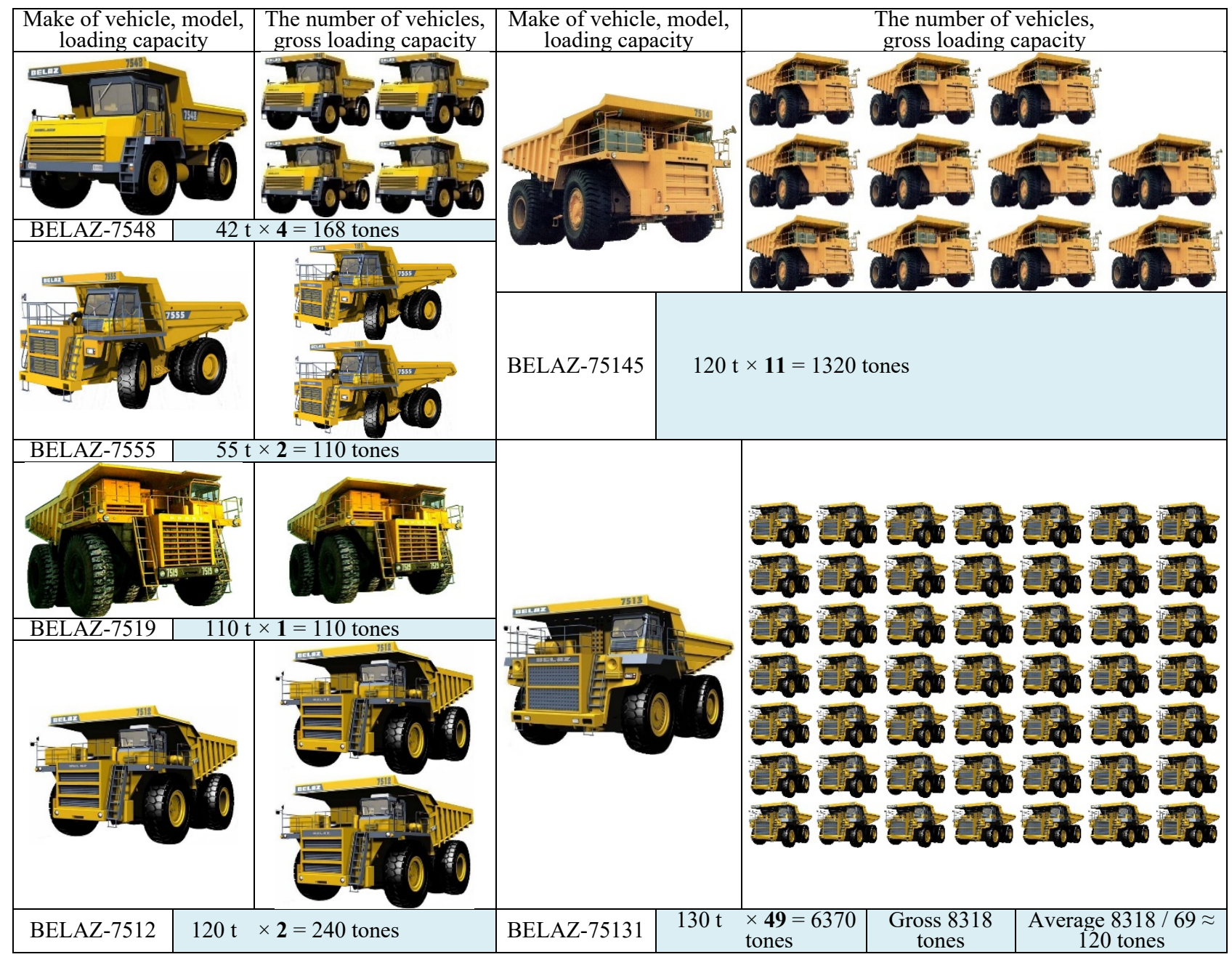


The criterion allows realizing the optimal control problem from the perspective of the developed mathematical model, which reproduces the Markov process occurring at the STAT [11].

However, it has to be previously demonstrated that it is possible for the mathematical model of STAT operation implementation to be used in the form of a Markov process. In order to get that done consider an identification problem with the composite function [11], which is minimized by the same parameters as the optimality criterion of the STAT (20):

$\sum_{i=1}^{N}\left(\left(t_{0 i}-T_{i} \cdot P_{0}\right)^{2}+\left(t_{1 i}-T_{i} \cdot P_{1}\right)^{2}+\left(t_{0 i}-T_{i} \cdot P_{0}\right)\right.$

$\left.\cdot\left(t_{1 i}-T_{i} \cdot P_{1}\right)\right) \rightarrow \underset{\lambda, \omega_{1}, \omega_{2}, \mu_{1}, \mu_{2}}{ }$,

where $T_{i}-$ is the observation time over technological states of $i$-th truck, running hours; $t_{0 i}, t_{1 i}, t_{2 i}-$ is the total actual time of $i$-th truck being in each of above technological states throughout $T_{i}$, running hours; $P_{0}=P_{0}\left(\lambda, \omega_{1}, \omega_{2}, \mu_{1}, \mu_{2}\right), P_{1}=P_{1}\left(\lambda, \omega_{1}, \omega_{2}, \mu_{1}, \mu_{2}\right)$, $P_{2}=P_{2}\left(\lambda, \omega_{1}, \omega_{2}, \mu_{1}, \mu_{2}\right)-$ are probabilities of truck being in each of three technological states.

Finding the values of the parameters rather a solution to the problem of STAT parametric identification was carried out by minimizing the composite function discrepancy (21). For the convenience of further calculations, this function can be written

$$
\begin{aligned}
& Q\left(P_{0}, P_{1}\right)=\sum_{i=1}^{N} T_{i}^{2} \cdot\left(\left(\frac{t_{0 i}}{T_{i}}-P_{0}\right)^{2}+\left(\frac{t_{1 i}}{T_{i}}-P_{1}\right)^{2}+\right. \\
& \left.+\left(\frac{t_{0 i}}{T_{i}}-P_{0}\right) \cdot\left(\frac{t_{1 i}}{T_{i}}-P_{1}\right)\right) \rightarrow \underset{\lambda, \omega_{1}, \omega_{2}, \mu_{1}, \mu_{2}}{\min }
\end{aligned}
$$

and apply the corresponding probabilities $P_{0}, P_{1}$ as the parameters where $\quad P_{1}=P_{1}\left(\lambda, \omega_{1}, \omega_{2}, \mu_{1}, \mu_{2}\right)$, $P_{0}=P_{0}\left(\lambda, \omega_{1}, \omega_{2}, \mu_{1}, \mu_{2}\right)$.

By minimizing the function (22), the optimal values were founded from certain parameters in response to parametric identification of the STAT

Given the rather short formula for the function (22), the problem of minimization is solved analytically. According to the necessary condition for the existence of an extremum, let us set partial derivatives by parameters $P_{0}$ and $P_{1}$ to zero.

$$
\begin{aligned}
& \left\{\begin{array}{l}
\frac{\partial Q\left(P_{0}, P_{1}\right)}{\partial P_{0}}=\sum_{i=1}^{N} T_{i}^{2}\left(-2\left(\frac{t_{0 i}}{T_{i}}-P_{0}\right)-\left(\frac{t_{1 i}}{T_{i}}-P_{1}\right)\right)=0 \\
\frac{\partial Q\left(P_{0}, P_{1}\right)}{\partial P_{1}}=\sum_{i=1}^{N} T_{i}^{2}\left(-2\left(\frac{t_{1 i}}{T_{i}}-P_{1}\right)-\left(\frac{t_{0 i}}{T_{i}}-P_{0}\right)\right)=0 .
\end{array}\right. \\
& \left\{\begin{array}{l}
2 \cdot P_{0} \cdot \overline{T^{2}}+P_{1} \cdot \overline{T^{2}}=2 \cdot \overline{T \cdot t_{0}}+\overline{T \cdot t_{1}} \\
P_{0} \cdot \overline{T^{2}}+2 \cdot P_{1} \cdot \overline{T^{2}}=2 \cdot \overline{T \cdot t_{1}}+\overline{T \cdot t_{0}} .
\end{array}\right.
\end{aligned}
$$

As a result, the system of two linear equations can be obtained

$$
\left\{\begin{array}{l}
2 \cdot P_{0}+P_{1}=\frac{1}{\overline{T^{2}}} \cdot\left(2 \cdot \overline{T \cdot t_{0}}+\overline{T \cdot t_{1}}\right) \\
P_{0}+2 \cdot P_{1}=\frac{1}{\overline{T^{2}}} \cdot\left(\overline{T \cdot t_{0}}+2 \cdot \overline{T \cdot t_{1}}\right)
\end{array}\right.
$$

We solve this system by Cramer formulas according to which a system of two simultaneous equations in two variables $P_{0}$ and $P_{1}$, matrix determinant that is not equal to zero

$$
\Delta=\left|\begin{array}{ll}
2 & 1 \\
1 & 2
\end{array}\right|=3 \neq 0
$$

and determinants

$$
\begin{aligned}
& \Delta_{0}=\left|\begin{array}{ll}
\frac{2 \cdot \overline{T \cdot t_{0}}+\overline{T \cdot t_{1}}}{\overline{T^{2}}} & 1 \\
\frac{T \cdot t_{0}}{T}+\overline{T \cdot t_{1}} & 2
\end{array}\right|= \\
& =\frac{4 \cdot \overline{T \cdot t_{0}}+2 \cdot \overline{T \cdot t_{1}}-\overline{T \cdot t_{0}}-2 \cdot \overline{T \cdot t_{1}}}{\overline{T^{2}}}=\frac{3 \cdot \overline{T \cdot t_{0}}}{\overline{T^{2}}} \\
& \Delta_{1}=\left|\begin{array}{ll}
2 & \frac{2 \cdot \overline{T \cdot t_{0}}+\overline{T \cdot t_{1}}}{\overline{T^{2}}} \\
1 & \frac{\overline{T \cdot t_{0}}+2 \cdot \overline{T \cdot t_{1}}}{\overline{T^{2}}}
\end{array}\right|= \\
& =\frac{2 \cdot \overline{T \cdot t_{0}}+4 \cdot \overline{T \cdot t_{1}}-2 \cdot \overline{T \cdot t_{0}}-\overline{T \cdot t_{1}}}{\overline{T^{2}}}=\frac{3 \cdot \overline{T \cdot t_{1}}}{\overline{T^{2}}}
\end{aligned}
$$

have closed-form solution

$$
\begin{gathered}
P_{0}=\frac{\Delta_{0}}{\Delta}=\frac{3 \cdot \overline{T \cdot t_{0}}}{3 \cdot \overline{T^{2}}}=\frac{\overline{T \cdot t_{0}}}{\overline{T^{2}}}, P_{1}=\frac{\Delta_{1}}{\Delta}=\frac{3 \cdot \overline{T \cdot t_{1}}}{3 \cdot \overline{T^{2}}}=\frac{\overline{T \cdot t_{1}}}{\overline{T^{2}}} \\
P_{2}=1-\frac{\overline{T \cdot t_{0}}+\overline{T \cdot t_{1}}}{\overline{T^{2}}} .
\end{gathered}
$$

\section{Results}

Table 2 provides statistics on the work of accountable BELAZ open-pit trucks in PJSC "Central GOK” open pit in 2015 (from the first mining workshop four trucks with utility numbers of $324,325,326,327$ were selected to facilitate parametric identification).

Given the average values of the parameters in table 2 which were determined with the aid of formulas (23) and (24), we obtain the probability values of an open-pit truck being in the state of operation, scheduled maintenance and unscheduled operating repairs respectively.

$$
\begin{gathered}
P_{0}=\frac{\overline{T \cdot t_{0}}}{\overline{T^{2}}}=\frac{62020800}{76737600}=0,808 ; \\
P_{1}=\frac{\frac{T \cdot t_{1}}{\overline{T^{2}}}}{=}=\frac{8168700}{76737600}=0,106 ; \\
P_{2}=1-P_{0}-P_{1}=1-0,808-0,106=0,086 .
\end{gathered}
$$

Following the indication on the technical manual [12] for BELAZ open-pit trucks, specified values of probabilities of vehicles being in the state of operation, scheduled maintenance and unscheduled operating repairs have the form respectively 
$P_{0}=\frac{7200}{8760}=0,822 ; P_{1}=\frac{900}{8760}=0,103 ;$

$P_{2}=\frac{660}{8760}=0,075$,

which are sufficiently close to the corresponding values of parametric identification (25).

The obtained values of probabilities (25) allow for the conclusion that the mathematical model of the system of technological automotive transport is sufficient. The analysis of the function (22) indicates its nonlinear dependence on the parameters whose values are optimized. As a result, it was decided to apply a numerical approach [13] to solve the problem of minimizing the function (21) which involves minimizing discordances $\lambda^{*}=0,00003015 ; \mu_{1}{ }^{*}=0,0002289 ; \mu_{2}{ }^{*}=0,057 ; \omega_{1}{ }^{*}=0,006$; $\omega_{2}{ }^{*}=0$.

Besides appropriate possibilities

$P_{0}=P_{0}\left(\lambda^{*}, \quad \omega_{1}^{*}, \quad \omega_{2}^{*}, \quad \mu_{1}^{*}, \quad \mu_{2}^{*}\right)=0,808$,

$P_{1}=P_{1}\left(\lambda^{*}, \quad \omega_{1}^{*}, \omega_{2}^{*}, \mu_{1}^{*}, \mu_{2}^{*}\right)=0,106$

align with parametric identification results (25).

Table 2. Data for the operation of accountable BELAZ open-pit trucks at PJSC "Central GOK" to parametric identification

\begin{tabular}{|c|c|c|c|c|c|c|c|c|}
\hline \multirow[t]{2}{*}{$\begin{array}{l}\text { Truck } \\
\mathrm{N}_{0}, i\end{array}$} & \multirow[t]{2}{*}{$\begin{array}{c}\text { Truck utility } \\
\text { number }\end{array}$} & \multirow{2}{*}{$\begin{array}{l}\text { Technological state } \\
\text { observation time for } i \text { - } \\
\text { th truck, } T_{i} \text {, running } \\
\text { hours }\end{array}$} & \multicolumn{3}{|c|}{$\begin{array}{l}\text { Total actual time } t_{k i} \text { when } i \text {-th } \\
\text { truck is in each of the three } \\
\text { technological states during } \\
\text { period } T_{i} \text {, running hours }\end{array}$} & \multirow[t]{2}{*}{$T_{i}^{2}$} & \multirow[t]{2}{*}{$T_{i} \cdot t_{0 i}$} & \multirow[t]{2}{*}{$T_{i} \cdot t_{1 i}$} \\
\hline & & & $t_{0 i}$ & $t_{1 i}$ & $t_{2 i}$ & & & \\
\hline 1 & $\frac{\pi}{0-1}(4) 4$ & 8760 & 6950 & 940 & 870 & 76737600 & 60882000 & 8234400 \\
\hline 2 & $\left.44^{4}\right)^{4}$ & 8760 & 7100 & 880 & 780 & 76737600 & 62196000 & 7708800 \\
\hline 3 & 4 & 8760 & 7120 & 930 & 710 & 76737600 & 62371200 & 8146800 \\
\hline 4 & 0 ta & 8760 & 7150 & 980 & 630 & 76737600 & 62634000 & 8584800 \\
\hline $\begin{array}{l}\text { Average } \\
\text { values }\end{array}$ & $0 \frac{1}{1+9}$ & 8760 & 7080 & 932,5 & 747,5 & $\overline{T^{2}}=76737600$ & $\overline{T \cdot t_{0}}=62020800$ & $\overline{T \cdot t_{1}}=8168700$ \\
\hline
\end{tabular}

\section{Conclusion}

Consider the obtained convergence of specified (26) and numerically calculated values of the STAT parameters (25) and (27), it may be deduced that an adequate mathematical model of the system of technological vehicles is synthesized, which is quite possible to apply for open-pit trucks operation optimization.

The calculated optimal controlling actions in the form of the intensity of planned measures towards open-pit trucks allow developing a technique for dynamic adjustment of maintenance parameters, diagnostics and repair of BELAZ open-pit trucks, which will become the foundation for a sustainable future of industrial transport operation.

\section{References}

1. L. Montiel, R. Dimitrakopoulos, Optimizing mining complexes with multiple processing and transportation alternatives: An uncertainty-based approach. Eur J. of Operational Research 247, 166178 (2015). doi:10.1016/j.ejor.2015.05.002

2. E. Topal, R. Salih, Min. truck scheduling with stoch. maint. cost. J. of Coal Sci. and Engineering (China). 18(3), (2012). doi:10.1007/s12404-012-0316-4
3. A. Moradi, S. Upadhyay, N. Askari, An integr. multi objective multi stage min. fleet management system linking dyn. operation to short-term plan. Paper presented at the SME Annual Conference and Expo and 91st Annual Meet. of the SME-MN Section, At Minneapolis, MN, 25 - 28 February 2018

4. Yu.A. Monastyrskiy, V.V. Potapenko, Modeling of technological conditions and analysis of events of functioning BELAZ opencast trucks. Metallurgical and Min. Industry 8, 480-484 (2015)

5. P.L. Mariev, A.N. Kuleshov, A.N. Egorov, Opencast avtotransp. status and prospects (Science, SPb., 2004)

6. P.L. Mariev, A.N. Kuleshov, A.N. Egorov, Opencast avtotransp. of CIS in 21 century (Science, SPb., 2006)

7. P.L. Mariev, Heavy-duty min. dump trucks. Des., technology, marketing (Interpolygraph, Minsk, 2008)

8. A.V. Vesnin, V.O. Sistuk, A.O. Bogachevskiy, Mathematical models analysis for the thermal state of min. trucks traction motors determining. Metallurgical and Min. Industry 3, 279-282 (2015)

9. X.-W. Gu, Q. Wang, X.-C. Xu, J.-P. Liu, T.-W. Sun, $\mathrm{K}$. Du, Open pit waste remov. optimization equip. fleet scheduling. Transactions of Nonferrous Metals 
Society of China 27(12), 2682-2690 (2017). doi:10.1016/S1003-6326(17)60297-8

10. Y. Chang, H. Ren, S. Wang, Modelling and optimizing an open-pit truck scheduling problem. Discrete Dynamics in Nature and Society 8 (2015). doi: $10.1155 / 2015 / 745378$

11. Yu.A. Monastyrskiy, Identification of parameters of open pit transportation system model. Paper presented at the Novitni shlyahi stvorennya, tehnichnoyi ekspluatatsiyi, remontu i servisu avtomobiliv, Viyskova akademiya, Odessa, 8-11 September 2015

12. Polozhenie o tehnicheskom obsluzhivanii, diagnostike, remonte karernyih samosvalov BelAZ (Regulation on the maint., diagnosis and repair of BelAZ min. dump trucks). (Rupp "BelAZ", Zhodino, 2004)

13. Mathsoft Mathcad 11. Users guide (2002)

14. M.J.F. Souza, I.M. Coelho, S. Ribas, H.G. Santos, L.H.C. Merschmann, A hybrid heuristic algorithm for the open-pit-min. operational plan. Problem. Eur. J. of Operational Research 207, 1041-1051 (2010). doi:10.1016/j.ejor.2010.05.031

15. V.N. Coelho, M.J.F. Souza, I.M. Coelho, F.G. Guimaraes, T. Lust, R.C. Cruz, Multi-objective approaches for the open-pit min. operational plan. Problem. Electronic Notes in Discrete Mathematics 39, 233-240

(2012). doi:10.1016/j.endm.2012.10.031

16. M.E. Villalba Matamoros, R. Dimitrakopoulos, Stoch. short-term mine prod. schedule accounting for fleet allocation, operational consid. and blending restrictions. Eur. J. of Operational Research 255, 911-921 (2016). doi:10.1016/j.ejor.2016.05.050

17. I. Temkin, S. Deryabin, I. Konov, Soft computing models in an intellect. open-pit mines transport control system. Procedia Computer Sci. 120, 411416 (2017). doi:10.1016/j.procs.2017.11.257

18. A. Moradi, N. Askari, Min. fleet management systems: a review of models and algorithms. International J. of Min. Reclam. and Environ. 31, 4260 (2017). doi:10.1080/17480930.2017.1336607

19. P. Knights, P. Oyanader, Best-in-class maint. benchmarks in Chilean open pit mines. CIM Bulletin 98, 1-6 (2005)

20. M. Moniri, M. A. Pourgol, Application of reliabilitycentered maint. for productivity improvement of open pit min. equip: Case study of Sungun Copper Mine. J. of Central South University. 21, 2372-2382 (2014). doi:10.1007/s11771-014-2190-2

21. Yu.A. Bahturin, Modelirovanie raboty slozhnyh transportnyh sistem karerov (Opencast complex transport systems modelling). (Gornyj informacionno-analiticheskij byulleten, Moscow, 2011)

22. A.A. Kuleshov, Sposoby povysheniya kachestva funkcionirovaniya sistem karernogo avtotransporta $v$ sovremennyh usloviyah (The methods of quality improvement of open-pit automotive transport system operation in the current context). (Gornyj informacionno-analiticheskij byulleten, Moscow, 2007)

23. O.P. Levkivskij, Strategiya rozvitku avtoremontnogo virobnictva $v$ period globalnih transformacij (Development strategy of auto-repair services for a period of worldwide changes). (Upravlinnya proektami, sistemnij analiz i logistika, Kyiv, 2005)

24. P.R. Levkovec, Upravlinnya proektami virobnictva $i$ tehnichnoyi ekspluataciyi avtotransportnih zasobiv (Project management for vehicles manufacture and operation). (NTU, Kyiv, 2006)

25. K.N. Trubeckoj, Sovremennye sistemy upravleniya gorno-transportnymi kompleksami (Modern systems of mining and transport management). (Nauka, SPb, 2007)

26. A.P. Pavlov, Teoriya potenciala rabotosposobnosti $i$ remontnogo rezervirovaniya nadezhnosti stareyushih tehnicheskih sistem (The theory of deteriorating technical systems performance potential and reliability repair reservation). (MADI, Moscow, 2013)

27. E.J. Henley, H. Kumamoto, Reliability engineering and risk assessment (Prentice-Hall, New Jersey, 1981)

28. L.N. Aleksandrovskaya, Sovremennye metody obespecheniya bezotkaznosti slozhnyh tehnicheskih sistem (Advanced technique of complex technical systems reliability assurance). (Logos, Moscow, 2001)

29. Yu.A. Bahturin, Opencast mining processes simulation models and management information systems integration backgrounds. Paper presented at the Problemy karernogo transporta, UrO RAN, Yekaterinburg, 12-14 October 2011.

30. V.B. Varaksin, Opyt ekspluatacii tehniki “BelAZ” v karerah gornodobyvayushih predpriyatij Kazahstana (The best operating practices of BelAZ equipment at open pits in Kazakhstan). (Gornyj zhurnal, Moscow, 2004) 